\title{
8. A Case Study: Tem de Tank
}

\begin{abstract}
In this chapter the theoretical model for the study of persuasive communication in digital games presented in chapter five, and the six factors that determine the conceptualization of persuasive strategies for advergames presented in chapter six, are used for the analysis of the advergame Tem de Tank, launched in 2010 by Volkswagen to introduce the Polo BlueMotion. Although the advergame's goals were properly defined, the game also contains a series of problems in terms of how the persuasive strategy was implemented. This game is therefore a perfect case study to exemplify how the theoretical model presented in this book can be useful to identify problems and propose solutions in the persuasive strategy of an advergame.
\end{abstract}

Keywords: case study, advergames, persuasive communication, persuasive games, theoretical model

In the sixth chapter I proposed a new theoretical model for the study of persuasiveness within digital games that can also be used for the implementation of persuasive strategies within digital games. I complemented this theoretical model with the identification, in the seventh chapter, of six factors that should guide the design of advertising strategies for advergames. In this chapter, I use a case study to illustrate how the knowledge provided in previous chapters can be employed for the study of persuasive communication within advergames. The game selected for the case study is Tem de Tank (DDB Amsterdam \& Flavour, 2010). Tem de Tank was launched in 2010 by Volkswagen as part of a 360 -degree integrated campaign to introduce the Volkswagen Polo BlueMotion. The Polo BlueMotion was designed to be environmentally friendly and was Volkswagen's response to customers' beliefs that the most important issue for the auto industry was tackling environmental issues. The car had lower fuel consumption and $\mathrm{CO}_{2}$ emissions and was the first step in the

De la Hera, Teresa, Digital Gaming and the Advertising Landscape. Amsterdam: Amsterdam University Press, 2019. DOI 10.5117/9789462987159_CHO8 
brand's efforts to become the "greenest automaker globally" (Volkswagen Group, 2011, pp. 5-8).

As part of the campaign to introduce this new version of the Polo, Volkswagen launched Tem de Tank in Holland aiming to make Dutch players aware about the energy efficiency of the car and also to create awareness of the influence drivers have on fuel consumption. In order to convey the advertising message, the designers created a game in which the player's goal was to drive a Volkswagen Polo BlueMotion from Amsterdam to Milan using only one tank of fuel and to arrive at the final destination with as little combustible material left as possible. In order to do this, the players needed to make a series of decisions that influenced the fuel consumption of the car.

The reason for selecting this game as a case study is that although the advergame's goals were properly defined, the game also contained a series of problems that resulted, from my point of view, in an inefficient game in terms of persuasion. I consider that most of the flaws in this advergame result from a lack of deep understanding of how digital games can convey meaning and how they can be designed to persuade players. Therefore, this game is a perfect case study to exemplify how this method can be useful to identify problems in the persuasive structure of advergames.

This chapter is divided into three parts. In the first part I identify and analyze the advertising strategy of Tem de Tank using the six factors identified in chapter 7 . Then, in the second and third sections, I use the theoretical model presented in chapter 6 to conduct an in-depth analysis of the persuasive structure of the advergame. First, in the second section of this chapter I analyze in-depth all the persuasive dimensions that have been used within the advergame to persuade players and how these persuasive dimensions have been used to implement the advertising strategy selected for the game. Then, in the third section of this chapter I identify and analyze the persuasive structure of the advergame as a whole.

\section{Tem de Tank's Advertising Strategy}

\section{Tem de Tank's Advergame's Objectives}

On the one hand, the advertising goals of Tem de Tank were to make players aware of the energy efficiency of the car and also to create awareness of the influence drivers have on fuel consumption. On the other hand, the game goals were to drive a Volkswagen Polo BlueMotion from Amsterdam to 
Milan using only one tank of gasoline and to arrive at the final destination with as LITTLE fuel left as possible.

In this case, designers decided to create an advergame in which the advertising goals and the game goals overlap. The first advertising goal, which is to make players aware of the energy efficiency of the car, overlaps with the first game goal, that is to arrive in Milan using only one tank of fuel. Similarly the second advertising goal, which is to create awareness of the influence drivers have on fuel consumption, overlaps with the second game goal, which is to arrive at the final destination with as little fuel left in the tank as possible. Therefore, in order to succeed in the game players need to understand the advertising message. However, when I played and analyzed the game for the first time I did not realize that the game goal was to arrive in Milan with as LITTLE fuel as possible. The reason for selecting this strategy was to prove the low fuel consumption of the car and to balance the game at the same time, it is a challenge to arrive with a tank almost empty in Milan because of the car's low fuel consumption. Nevertheless, I consider that this goal is not clearly communicated within the game, and this lack might have generated problems in terms of persuasion. I will discuss this point later in detail.

The decision to create an advergame in which game goals and advertising goals overlap is in this case a good strategy because the advertising goals are not related to changing players' ideas or beliefs but with making them aware of the advantages of the Volkswagen Polo BlueMotion. When the intention is to change players' beliefs, there might be a conflict when game goals and advertising goals overlap because players might act as if they agree with the ideas proposed in the game simply in order to win the game. In Tem de Tank the situation is totally different because there should not be any conflict between players' beliefs in the physical world and their getting the advertising message and using the information obtained within the game to win it.

However, the selection of the advertising goals might be detached from the campaign's objectives. The BlueMotion line of Volkswagen was launched with the aim of making VW the greenest automaker globally. Volkswagen's objective is to communicate that BlueMotion cars are environmentally friendly, and the advertising goals of the game are focused on communicating that the Polo is a low-fuel-consumption car. Yet I cannot find any claim in the game that using less fuel is good for the environment. Even though there is an implicit relationship between the low use of combustible fuel and respect for the environment, the latter is not the focus of the advertising message conveyed through the advergame. 


\section{Tem de Tank's Product Integration}

In this section I will take into account the advertising goals pursued by the designers and ignore the goals of the campaign mentioned above. I do this because regardless of whether there is a gap between the campaign's goals and the advergame's goals, the advergame's goals are still related to the benefits of the car and are coherent with the brand and the product advertised. Therefore, my objective here is to evaluate whether the decisions made concerning the design of the advergame are adequate considering the advergame's objectives.

As stated above, one of the goals of the game is to drive a Volkswagen Polo BlueMotion from Amsterdam to Milan. In order to do this, the player has to control a photographic representation of the vehicle along a graphic simulation of the road between Amsterdam and Milan. To drive the car, players need to use the arrow keys of the keyboard which allow them to accelerate or to turn left or right. Furthermore, using two selectors on the interface players can also decide to use the air conditioning or to open the windows. In addition, by pressing the space bar players can activate the cruise control to control the speed of the vehicle. This advergame, therefore, lies somewhere in between an illustrative advergame and a demonstrative advergame (see Figure 22) because although the car is integrated into the game in its natural context, a road, the game does not allow players to interact with it in the way they would in the physical world.

On the basis of the above, I claim that in this case the game lies in between an illustrative and a demonstrative advergame, and it takes advantage of both forms of advertising. Demonstrative advertising provides direct information about the nature of a product. An example of demonstrative advertising in the game is the fact that the player needs to complete a driving route using only one tank of fuel by making decisions related to that action in the physical world. The fact that the game is a digital simulation of driving the car introduces elements into the game experience that help to convey the advertising message, such as objects that players need to collect on their way. These elements could not be used in a physical environment.

\section{Tem de Tank's Advergame's Target}

The targets of the advergame in this case were young people, especially men, between 25 and 35 years old with an interest in environmentally 
Associacive

Advergames

(Absence of the

Product)

TEM DE

TANK

Illustrative

Advergames
Demonstrative

Advergames

(Full

Integration)

Figure 22. Integration of the product in Tem de Tank (DDB Amsterdam \& Flavour, 2010).

friendly and fashionable cars with low taxes ${ }^{1}$. According to the Interactive Software Federation of Europe, 8 out of 10 Dutch males between 16 and 35 years old are gamers, and $55 \%$ of them usually play online games (ISFE, 2012, p. 7). Compared to other age and gender groups, the target group of the advergame analyzed here is the group that plays more games online (2012, p. 9). Therefore, the strategy to select a game to advertise the Polo BlueMotion is a good one given the age and the gender of the target group. It follows that a positive attitude of this target group toward a game as a form of advertising can be expected. However, as I will explain in depth later, the game presents serious problems in terms of playability that might have negative consequences on the final attitude of players toward the advertising message.

Furthermore, even though the designer's target group is young men with an interest in environmentally friendly cars, the game does not include any clear argument related to the benefits of the use of the car for the environment. On the contrary, the advergame is focused only on the low fuel consumption of the car, which is interesting only for those who want to save money on fuel. Although there is an indirect relationship between low fuel consumption and low $\mathrm{CO}_{2}$-emissions, the latter is not the focus of the advertising message conveyed through the advergame.

\section{Tem de Tank's Advergame's Visibility}

In this case the brand decided to design an online advergame and place it on a microsite under the domain of Volkswagen. ${ }^{2}$ The brand opted to launch its game primarily for the Dutch market. The decision therefore was to

1 The game was released in Holland where taxes are lower for cars with low emissions.

2 During the campaign, the game was placed on the microsite www.volkswagen.nl/temdetank/. 
launch the game only in Dutch. This decision left out non-Dutch speakers, who were not going to play the game even if they had access to it due to language limitations. Furthermore, the game was available only during the one month of the campaign, and it was removed from Volkswagen's domain after that. Additionally, the game took advantage of the total control of the content that a microsite provides and designed a game totally adapted to the advertising goals. All these decisions were appropriate given the objectives of the campaign.

The placement of the advergame on a microsite created a disadvantage concerning visibility and necessitated an extra effort to make players aware of the existence of the game. In order to overcome this disadvantage, the brand decided to publicize the game on the radio and to make use of viral marketing through Hyves and blogs. In less than one month the game was played 170,000 times by more than 100,000 unique players. Therefore, it can be concluded that in terms of visibility the work done was in keeping with the objectives of the campaign.

\section{Tem de Tank's Advergame's Credibility}

In this section I analyze Tem de Tank (DDB Amsterdam \& Flavour, 2010) in relation to the factors that might have affected its credibility, namely the extent to which players perceived claims made about the Polo BlueMotion within it to be truthful and believable. For that purpose, I examine (1) players' perception of the brand's truthfulness or honesty, and (2) the perceived doubts players might have had about Tem de Tank's claims.

Firstly, Volkswagen is a brand with a high reputation, namely "what consumers perceive the brand to stand for" (van Gelder, 2003, p. 107). In 2012 VW was ranked among the top three brands with the highest reputations in the world according to the Reputation Institute, the world's leading reputation management consultancy (2012). It follows that players would have been expected to have a high level of trust in Volkswagen. Furthermore, although the BlueMotion was a new version, the Polo, as a model, has existed for a long time, and it could be expected that its reputation would be linked to the new version of the model. Thus the advergame did not need to make a big effort in generating familiarity and loyalty for the brand. It follows that the advergame lay in between a response-shaping and a response-reinforcing game because it had to introduce a new version of the Polo and present players its benefits as an energy-efficient car, but at the same time, the advergame could rely on previous customers' loyalty to the brand. 
The game promised players that it is possible to get from Amsterdam to Milan on only one tank of fuel by making efficient use of the Polo BlueMotion. I have previously claimed that the procedural and interactive nature of advergames allows them to deliver meaningful experiences, instead of just promising them, which may help to overcome players' doubts about their claims. However, in this case there are some features of the game that might have led players to think that the argument that it is possible to drive from Amsterdam to Milan with only one tank of fuel might be only a promise and not an experience that they could verify in the game.

The game supposedly provides a driving experience in which the consumption of fuel is realistic and calculated according to the performance of the player. However, there are a series of features in the gameplay that are not convincing, which decreases the credibility of the experience. At the beginning of the game, for example, players need to decide with how many passengers they want to travel with to Milan. That decision has repercussions for the consumption of fuel during the journey. However, during the trip, the player can collect or get rid of luggage and passengers with the intention of arriving with as little fuel as possible at the final destination. This is not realistic at all because when people take long trips, they do not collect or get rid of passengers indiscriminately. Furthermore, the player can also collect icons that correspond to weather conditions, thereby influencing fuel consumption; however, in the physical world the weather is not something that can be changed by a driver during a trip. Therefore, the possibility given to the player to control the consumption of fuel with these actions detracts from the credibility of the claim that is possible to drive from Amsterdam to Milan with one tank of fuel, thereby make the game a less than realistic experience.

So, although the game starts from a good position in terms of credibility, some decisions made related to the games' playability do not help to reinforce it. Small changes that are proposed in this chapter would help to overcome this drawback and to reinforce the credibility of the advergame's claims.

\section{Tem de Tank's Advergame's Playability}

In this section I evaluate the playability of Tem de Tank, namely the degree to which the game is fun to play and is usable, according to the following attributes: motivation, learnability, memorability, efficiency, utility and satisfaction.

In terms of motivation Tem de Tank used an appealing strategy to encourage players to join the game. This was the final prize that allowed the three 
players who performed best during the month the game was available on the microsite to participate in a physical event in which the best of the three won a Polo BlueMotion. Undoubtedly, the possibility to win a car was an important motivation for most of the players not only to play the game for the first time, but also to keep playing to improve their performance. Furthermore, the fact that the final goal of the physical event was the same as the digital game might have also served to motivate players to pay attention to the indications given throughout the game on how to drive efficiently.

However, there are some faults in terms of learnability that might have affected the understanding of the challenge and therefore players' motivation. The first problem is that the challenge of the game is not properly presented to the player before he/she begins playing it. On the first screen of the game the player reads the following message: "Met de Polo BlueMotion rij je op 1 tank naar Milan. Sterker nog, léég aankomen is een hele uitdaging” ("With the Polo BlueMotion you can drive with one tank [of fuel] to Milan. Indeed, arriving on empty is a quite a challenge"). ${ }^{3}$ With this text the player might have understood that the goal of the game is to arrive in Milan without fuel because that action is presented as a challenge. However, the text immediately continues: "Tem de tank en kom met de minste hoeveelheid diesel in Milan aan" ("Tame the tank and get to Milan with as little fuel as possible left"). ${ }^{4}$ It follows that the player might have been confused about the real objective.

Furthermore, the text explaining the challenge appears in a very small font in the upper-left corner of the screen. Therefore, it is possible that some players began directly playing without reading the challenge of the game. Since Tem de Tank looks like a racing game, the lack of emphatic presentation of the challenge can lead players to conclude that the objective of the game is to arrive at the final destination as quickly as possible. And in fact, it is possible to arrive in Milan without consuming the tank of fuel with this objective in mind. It follows that it is possible to finish the game without understanding the objective of the game. Moreover, at the end of the game there is no clear feedback about the result of the performance. This means that it is possible to finish the game without understanding its goal and thinking that the performance was correct. This major flaw related to the learnability of the game might mean that many players did not get the advertising message at all, even after playing the game more than once. 
There are also a series of elements in the interface of the game that need to be understood and controlled in order to perform well but also in order to get the advertising message. By making use of buttons in the interface players can control some features that influence fuel consumption. They can decide whether to use the air conditioning, whether to open or close the windows, and whether to use cruise control. ${ }^{5}$ The presentation of those elements and what they are useful for is made in a small slideshow on a loading screen before the game starts. This slideshow runs too quickly and the font-size of the texts of the explanation is too small. Therefore, it is really difficult to read and understand the explanations about controlling those elements. Again, this causes problems in understanding how to perform in the game, which also has consequences for the transmission of the advertising message.

In addition, I also found problems in the game related to efficiency, namely the way the game supports players in achieving the objectives and reaching the final goal. On the one hand, I think that the goal of the game is well chosen because even if the game is easy to play, the challenge of arriving at the final destination on as little fuel as possible serves to balance the game. Furthermore, the challenge also encourages players to keep playing once they have finished, with the purpose of improving their result. However, the problems with the presentation of the challenge undoubtedly cause problems of efficiency.

Moreover, there is a serious problem related to the way the player has to interact with the game, which also results in problems of efficiency. Players need to control the car using the arrow keys on their keyboards. However, there are other elements in the game that need to be controlled by players at the same time that they are driving the car. For example, the player is encouraged to open or close the windows, to use the air-conditioning or to choose between different routes during the journey. Surprisingly, the player has to use the mouse to control those elements in the game. I say surprisingly because players usually control the arrow keys with the same hand they control the mouse. Therefore, the game is asking players to lose control of the car if they want to control the rest of the elements in the interface. This is without doubt a serious flaw in terms of efficiency, leading players to focus on control of the car and forgetting about the other options. Consequently, the efficiency of the transmission of the advertising message is reduced because the player does not experience the fuel-consumption consequences of using these features.

5 Cruise control is a system that automatically controls the speed of the car, thus reducing the consumption of fuel. 
These problems might also have consequences for the advergame's utility, namely what allows players to carry out the tasks they have to complete in the way they want. Utility is related to players' freedom within the advergame. In this case although players' freedom is limited, there are a series of decisions that they can make and that have consequences for the final outcome. However, if the players do not understand what they have to do in the game, the utility provided becomes meaningless.

Finally, satisfaction, the pleasure derived from playing the advergame, is a subjective property difficult to evaluate in this analysis. Nevertheless, the strategy of using the physical challenge as a prize for the three best players might have generated extrinsic pleasures ${ }^{6}$ for those players who were on the leaderboard during the month the game was online, and for those who finally were offered the opportunity to face the challenge. Therefore, the strategy of the game was able to generate pleasure that could be experienced after playing the game and that might have had positive consequences on player's lives that they might have linked to the brand.

In conclusion, although the challenge of the game is well designed and there is a balance between the difficulty of controlling the game and the difficulty of mastering the game, Tem de Tank's advertising strategy presents problems that might have had consequences in the transmission of the advertising message.

\section{Tem de Tank's Persuasive Dimensions}

In this section I analyze how the advertising strategy described in the previous section has been implemented within the Tem de Tank by making use of different persuasive dimensions. Furthermore, I evaluate whether the use that has been made of the different persuasive dimensions helps to convey the advertising message, or, on the contrary, if there are contradictions or flaws that may have affected the transmission of the message. The persuasive dimensions considered in the theoretical model described in chapter 6 but not discussed in this section have not been used within this advergame, namely sonic persuasion, cinematic persuasion, sensorial persuasion, affective persuasion and tactical persuasion. In the next section I will discuss the pertinence of the decisions made in this regard. 


\section{Tem de Tank's Linguistic Persuasion}

Linguistic persuasion is used within Tem de Tank with three purposes: to make players aware about the energy efficiency of the Polo BlueMotion, to create awareness of the influence drivers have on fuel consumption, and to communicate other features of the car. The first two purposes are related to the goals of the game, which facilitates their introduction in the game. However, the third purpose is not related to the game goals, and therefore, it has to be introduced carefully in the game to avoid resistance.

Linguistic persuasion is used to make players aware of the energy efficiency of the Polo BlueMotion in the first screen of the game when the objective is presented. In that screen the player reads: "Met de Polo BlueMotion rij je op 1 tank naar Milan. Sterker nog, léég aankomen is een hele uitdaging" ("With the Polo BlueMotion you can drive with one tank [of fuel] to Milan. Indeed, arriving on empty is quite a challenge"). ${ }^{7}$ This is the only moment in which linguistic persuasion is used to inform the player that it is possible to drive from Amsterdam to Milan with one tank of fuel. In this case, designers are using inductive reasoning to convince the player that the Polo BlueMotion is an energy-efficient car. Inductive reasoning is facilitated by using as an example a journey that players know is long and making them aware that there is a possibility of completing the whole route on only one tank of fuel. Furthermore, in this case players might have not perceived the argument as an intrusive form of advertising because it is used to present the challenge of the game.

However, there is a problem with how the aforementioned text is presented to the player. As explained above, the text appears in a very small font in the upper-left corner of the screen while centered on the screen in a bigger font, highlighted as a button, there appears a text reading "Speel de game" ("Play the game"). ${ }^{8}$ It is thus possible that some players did not read the text properly and therefore were not persuaded by the linguistic persuasive message. Because this is an important message and designers have to be sure that players have understood it, repetition should be used to ensure that players get the message. The message should also appear in a bigger font to attract players' attention.Linguistic persuasion is also used to make players aware about the energy efficiency of the car at other points during the journey. At some points of the trip, the game prompts some questions about the route the player wants to follow. Once the player has

$7 \quad$ Translated by the author from Dutch into English.

8 Translated by the author from Dutch into English. 
selected one of the options, the system prompts a new message in which it explains the benefits of choosing that route related to fuel consumption and the enjoyment of the trip. This system is also used to communicate other features of the car, such as its tight steering.

In this case there are two problems. The first problem is that the text appears while the player is driving the car. At the moment that players see the message, they also see in the background their car moving on the road. In fact, the background is moving, but the game is paused for a while. That is, there is no possibility for the car to bump into something. However, the moving background makes players feel that they need to keep controlling the car, so it becomes difficult to concentrate on the question, on the two possible options or moreover on the final explanatory text. The second problem is that the text is quite long and reading it is not useful for the player in the game. Therefore, it can be perceived as an intrusive persuasive message, which can result in player's resistance.

In addition, the text that is prompted after the player has chosen a route is not adapted to the player's performance. The text always congratulates players on their decision, no matter what the decision is and what their performance has been up to that point. For example, at one point during the journey the game communicates to players that there are road-works on the route they are following and gives them two options: to follow a short route that passes through small villages or to follow the detour route, which is longer. The text that players see if they choose the first option is: "-8 liter diesel. Good choice. Traffic lights are unfavorable for fuel consumption, but thanks to the smart start-/stopsystem of the Polo BlueMotion you can limit the loss." The text that players see if they choose the second option is: "- 4 liter diesel. Very wise decision. This way you can keep driving at a constant speed, which is good for your consumption."

The reason why both texts are written this way is that they are used in the game only to communicate the advertising message but not to give feedback to players about their performance in the game. This is a flaw; because the system is asking players to make the effort of reading the text, players interpret that reading as providing information needed to understand how to play the game. If the system congratulates players on their decision, they understand that they made a good choice. However, that is not always true because the text prompted is always the same, no matter what the player's performance has been up to that moment. For example, in the aforementioned example, the game should congratulate players if they choose the first option if they have too much fuel left because that option would help them to arrive with less fuel left in Milan. On the other hand, 
the text should advise them to take care if they are wasting too much fuel because choosing the first option would not help them to win the game.

There is an additional problem with these texts: they provide information that does not match the options provided by the system. For example, in the case I am analyzing here, the game congratulates the player for choosing the first option because it says that it is possible to limit the consumption thanks to the smart start-/stopsystem. However, the game already informs players that the amount of diesel used on that route will be eight liters, so players cannot experience how the smart start-/stopsystem is helping them to reduce consumption.

Consequently, all the above can result in distracted players, who get no clear feedback about the implications of their decisions for the final outcome of the game because they find contradictory information. Furthermore, if players realize that the text is not helping them to improve their performance, they are going to perceive it as intrusive communication, and probably their perception of the advergame is going to change.

Finally, linguistic persuasion is also used in the game to create awareness of the influence drivers have on fuel consumption. In this case, the game uses texts that are presented to players as tips that they can use to improve their performance in the game. Those tips make them aware about the consequences on fuel consumption of using the air conditioning or of opening the windows, for example. This is a good strategy taking into consideration the advertising goals and the game goals. The texts can help players improve their performance in the game and at the same time serve to transmit the advertising message. However, again I find problems in the way the texts are presented to players. The texts appear in a small font in the lower-left corner of the screen and only for a few seconds. This makes it difficult for players to read them because players need to concentrate on controlling the car at the same time. Furthermore, the texts are written in white, and sometimes it is difficult or even impossible to read them depending on the background. In some specific moments, for example, there are white clouds that pass under the texts that make it totally impossible to read them. Given that the texts appear only for a few seconds, some tips are totally missed because of this.

I would suggest changing the way the tips are introduced and making them appear in relation to players' performance. For example, if players are wasting too much fuel the game would prompt a message warning them about this fact and suggesting a solution. This would reinforce the advertising message but also make players more aware about their performance and how it can be improved. The tips would thus become more meaningful for 
players who would probably then pay more attention to them. Given that the attention of players is focused on the top of the screen, because they are concerned about what comes next, I would also suggest changing the position of the tips to the upper-right corner.

\section{Tem de Tank's Visual Persuasion}

Visual persuasion is used within Tem de Tank with two purposes: to enhance the designs of the Polo BlueMotion and to make players aware of the influence drivers have on fuel consumption. The most salient decision related to visual persuasion within the game is the introduction of a photographic representation of the car while the rest of the elements of the game are part of a $2 \mathrm{D}$ graphic design. This decision has two positive consequences in terms of persuasion. The first consequence is that the difference in the visual presentation of the car draws players' attention to the vehicle. The second consequence is that the player can have a clear idea about how the car looks in real life.

Since the target for the designers includes young men interested in fashionable cars, the design of the car becomes an important feature to be presented to players. In this case, players have the opportunity to see three photographic images of the Polo. The first image is placed on the home screen in which the challenge of the game is presented. On that screen the car appears large, centered on the screen, drawing players' attention to the vehicle.

The second image is placed on the screen in which players can decide how many passengers they are taking with them on the trip. In this screen players can see a new photograph of the car in which it is seen from behind with the doors open. Again, the car appears large, centered on the screen, drawing players' attention to the vehicle. Given that the screen is focused on choosing passengers for the trip this would have been a good opportunity to present the interior of the car and/or the size of the trunk of the car.

Finally, the third image is the car that players can drive in the game. In this case players can see the car from above, and it appears in a small size on the screen. Therefore, players do not get extra information from this, but it helps them to keep in mind the information that they got from previous images.

Visual persuasion is also used in the game to make players aware about of the influence drivers have on fuel consumption, for instance in the visual design of the suitcases and the passengers that players can collect along the journey. This feature was designed to make players aware about the influence 
that weight transported has on fuel consumption. Players can pick up new passengers or suitcases by collecting iconic representations of them with a "+" symbol, and they can get rid of passengers and suitcases by collecting iconic representations of them with a "-" symbol. Furthermore, "+" signs are represented in red and “-” are represented in green. By convention, red is associated with wrong actions while green is associated with good actions. The objective of using the red and green colors for these visual signs is to convey the advertising message that collecting red passengers and luggage is a negative decision in terms of fuel consumption while getting rid of green passengers and suitcases is a good decision to save fuel.

However, the visual design of the signs is quite confusing given the purposes of the game because the objective is to arrive in Milan with as little fuel remaining as possible. Therefore, when the player has too much fuel left, picking up a new piece of luggage can be a positive and not a negative action. The use of the green and red colors in this case might have caused confusion because the colors are related only to the communication of the advertising message but not to the goals of the game. Consequently, some players might have been distracted by the use of these colors.

Finally, there is also a problem with the visual design of the "actieradius meter", an element designed to serve as an indicator of the players' performance regarding fuel consumption, supposedly helping them to have an idea whether they are wasting too much fuel or not consuming enough fuel according to the challenge. However, the visual design of this meter makes it difficult for players to decipher the information provided by it. Players are supposed to keep the pointer in the blue zone to achieve the best performance, but it is quite difficult to decipher what is going on when the player is not in the blue zone. At the two extremes of the meter there are two indicators: one that says "+100", which supposedly warns players that with the fuel left they can ride 100 kilometers beyond Milan; and another one that says "-100", which supposedly means that they are going to run out of fuel 100 kilometers before arriving in Milan. However, the arched representation and the use of the same color --red-- on both sides of the meter does not provide players quick feedback on what is going on.

A solution for a design of the "actieradius meter" could be to create a vertical meter in which the center represents arriving in Milan with as little fuel remaining as possible. In this representation players could see how the level of fuel goes up in a green color when they drive with too much fuel left and the level of fuel goes down into a red color when they are wasting too much fuel. The colors would increase and decrease in such a way that when the players see the red color they would understand that they are wasting 
too much and when they see the green color they would understand that they have a lot of fuel left. This design would help players to quickly grasp the meter's message just by identification of the colors. At the same time, it also would link the meter with the advertising message because the green color would mean getting to Milan on only one tank on fuel. This means that even players not on the high-score table would be able to finish the game.

Moreover, this new design of the "actieradius" would give sense to the color code used in the items the player needs to collect during the journey. As explained before, items are designed in two colors, green and red, with green meaning that they are saving fuel when collecting them and red that they are wasting more fuel when collecting them. With this design players would also understand that collecting green items increases the level of the "actieradius" and collecting red items decreases the level of the "actieradius". Therefore, the color would be linked not only to the advertising message but also with the game goal.

In conclusion, visual persuasion is well used to present the visual design of the car to players. However, the use of visual persuasion to make players aware about the influence drivers have on fuel consumption might have not worked in the way intended. The problem is that the design was focused only on conveying the advertising message and paid insufficient attention to the consequences it could have on how players interpret the signs and their implications for the game.

\section{Tem de Tank's Haptic Persuasion}

Haptic persuasion is used within Tem de Tank only with the purpose of presenting the benefits of the cruise control of the Polo BlueMotion and the consequences of weather circumstances on the vehicle's control and fuel consumption. Cruise control is a system that, when activated, automatically controls the speed of the car, and thus reduces fuel consumption. Using cruise control also increases driving comfort because the player does not need to worry about pressing the accelerator pedal. Activating cruise control is as simple as pressing a toggle button.

In the advergame, the player can activate the cruise control of the Polo BlueMotion by pressing the space bar, which is as simple as pressing the toggle button while driving. After activating cruise control, the player can forget about pressing the up arrow key, which is used to accelerate the car. Thus, controlling the car in the game becomes easier.

Through the activation of cruise control and the interaction with the car through the use of the keyboard, players understand that activating 
cruise control in a car in real life is simple and can increase driving comfort. However, there is no clear feedback about the influence of the use of cruise control on the reduction of fuel consumption. The use of cruise control has influence on the final score, yet when the player decides to activate cruise control, there is no direct feedback about the consequences of this action. In this case, I would propose adding a prompt message placed in the upper-right corner of the screen that would use visual information to convey that using cruise control saves fuel. For this purpose I would use the "actieradius" with a green arrow pointing upwards. This could be quickly interpreted by players who would already know that green is associated with actions that save energy and who would also know that increasing the level of fuel saved may cause them to arrive in Milan with a combustible excess.

Haptic persuasion is also used when the player collects the signs that represent different weather conditions. For example, downwind causes acceleration in the car, rain causes deceleration and snow causes loss of control. However, these changes in speed and control are not obvious and might not be perceived by every player. In addition, when a sign is collected, this sign appears in the lower-right corner accompanied by a message that includes a number of kilometers. I suppose that this number corresponds to the number of kilometers' difference that the weather condition makes to the distance the driver can drive, but this is not clear and a little bit confusing. In order to improve the feedback given to players about the consequences of weather conditions I would suggest prompting a message similar to that proposed above for the cruise control system, in which the system would alert the player, for example, that upwind causes an increase in fuel consumption. This solution would help to make players aware about the influence of weather conditions on the car's performance.

\section{Tem de Tank's Procedural Persuasion}

Procedural persuasion is used within Tem de Tank again with the purposes of making players aware about the energy efficiency of the Polo BlueMotion and to create awareness of the influence that drivers have on fuel consumption. I am going to divide the analysis of the use of procedural persuasion into four parts according to the four different rule types that is possible to find within digital games: (1) goal rules, (2) grade rules, (3) meta-rules, and (4) model rules.

The goal rules define the stated aims that lead to victory. In Tem de Tank, the objective is to drive the Polo BlueMotion from Amsterdam to Milan on only one tank of fuel. Those players that use up the tank of fuel before 
reaching Milan lose the game. This goal rule helps designers to convey the message that the Polo BlueMotion is an energy-efficient car. However, as explained above, the form of presenting the game challenge is not ideal because the text is written in such a way that is not clear whether the final goal is to reach Milan with as little fuel as possible or with an empty tank. In fact, only those players who run out of fuel during the trip read a message that clarifies this objective, by communicating to those players that they have lost because they have run out of fuel.

The grade rules deal with any characteristic that is measured within the game. In the case of Tem de Tank the most important grade rule is the level of fuel left at the end of the trip. The game established that the three players who arrive in Milan with the least amount of fuel left would participate in a real competition of a similar nature. This grade rule became persuasive because it was designed to make players aware about their influence on fuel consumption. In this case, the grade rule guides players' interpretation of the visual design of the "actieradius" designed to give players feedback about the consequences of their performance in the game. However, I suggested some changes in the way this element is presented to players in order to improve the quality of the feedback and therefore facilitate the transmission of the advertising message.

Meta-rules define how the players can customize their own preferences. Players of Tem de Tank were provided with a series of elements that they could collect or modify in order to influence fuel consumption. This included collecting or getting rid of passengers and suitcases during the journey, the activation of the air conditioning, the use of the windows, the use of cruise control, and the collection of forecast signs that had consequences for the weather during the trip. All these elements are introduced into the game by making use of linguistic, visual and haptic persuasion, and their interpretation is guided by the rules of the game. Only when players experience the consequences of activating the air conditioning, for example, does the sign that represents it become meaningful for them and convey to them the advertising message.

Regarding the items that players can collect during the trip, I have already discussed the problems that I find with the visual design of passengers and suitcases. I have also explained that collecting and getting rid of passengers and luggage during a long trip is not a realistic occurrence, and thus it is a game feature that does not help the credibility of the advertising message. Furthermore, I have also stated my concern about the difficulty of controlling the car whilst paying attention to other elements such as the air conditioning and the windows. 
Since players can decide at the beginning of the trip how many passengers and suitcases they want to travel with, I would suggest removing the possibility of collecting these elements during the trip. Instead, I would replace those elements with other signs that represent the windows and the air conditioning. The resulting experience would be more realistic because switching the air conditioning on and off and opening and closing the windows several times during a journey are realistic options that have consequences for fuel consumption. At the same time, I would remove the actual controllers for the air conditioning and the windows, thus improving playability.

Furthermore, the weather is also something that cannot be controlled by players. For this reason and in order to improve the credibility of the advergame, I would suggest removing the possibility of collecting weather signs during the trip. I have also noticed that although at some points during the journey the roads splits and the player has to decide which way to follow, there are no direct consequences of choosing one route over the other. At least, there is no feedback about the consequences. I would therefore suggest adding signs indicating the weather forecast for the different routes the player can choose during the journey. Even if it is not normal to find weather signs on the road, the forecast for different routes is something that can be checked by drivers. Therefore, this solution is more realistic than the actual one and could serve to give credibility to the advertising message.

Finally, model rules define how the playworld works and therefore set the boundaries of players' activity. In Tem de Tank model rules are used with persuasive intentions associated with the weather conditions. When players drive in the rain the speed of the car is reduced, and when players drive in the snow there is also a maximum speed at which they can drive. However, while playing the game the difference is almost unnoticeable. Therefore the effectiveness of this model rule can be questioned.

\section{Tem de Tank's Narrative Persuasion}

In Tem de Tank narrative persuasion is used to reinforce the advertising message communicated through other persuasive dimensions and as an excuse to introduce new arguments about other features of the Polo BlueMotion. As I have previously explained, there are three moments during the trip in which the game prompts a question about the route the player wants to follow. When the player has selected an option, a new message appears explaining the benefits of having chosen the selected route. I have already highlighted some problems related to this strategy, and now I want to link those problems with a misuse of narrative persuasion. 
In this case designers opt for making use of scripted narrative to introduce the aforementioned arguments. For example, the second question tells players that a truck has lost its load of 30,000 eggs, creating a ten-kilometer traffic jam. The game then offers the player two options: to have a break and eat an apple tart or to continue on the road but drive slowly. If players choose the first option, the game prompts a message alerting them that they are going to use four liters of fuel and makes them aware that the integrated navigating system of the car will help them to come back to the main route after a while. On the other hand, if players choose the second option, the game prompts a message alerting them that they will use two liters of diesel and makes them aware that the seats of the Polo BlueMotion make it really comfortable for them to be waiting in a traffic jam.

However, right after players have taken their decision, they can continue driving the car on an empty road with no changes at all. Thus, even if they have chosen to continue driving they do not encounter a traffic jam or eggs on the road. The scripted narrative is obviously used to introduce the advertising message, but there are flaws in the way the advertising message is introduced. If players cannot see in the game the benefits of the comfortable seats or the navigating system, they are going to perceive the message as an intrusive form of persuasion. In this case the use of scripted narrative is not enough to avoid player's resistance.

\section{Tem de Tank's Social Persuasion}

In Tem de Tank I have identified an attempt to use social persuasion. However, the strategy followed to make use of this persuasive dimension in the game does not work as intended, as I explain below.

At the beginning of the game players needed to decide upon the number of passengers in the car and the number of pieces of luggage. At this point, players had the possibility to login with their Hyves ${ }^{9}$ account and to choose a maximum of four friends to become passengers on the trip. However, the connection with the Hyves account can be skipped, and the player can occupy the seats with anonymous passengers. At this point there is no explanation of the benefits of using real friends to occupy the seats, but previous experiences would make players think that choosing their own friends would result in cool stuff including pictures of all of them, for example. However, none of these possibilities happens; in fact, the game does not include any other reference about players' friends, not even when 
the game is finished. Furthermore, during the trip players discover that they can get rid of the passengers they are taking with them and that they can collect new anonymous passengers.

Consequently, players' expectations are raised but are ultimately unfulfilled. This means that the positive attitude aroused in players toward the advertising message might have been transformed into disappointment that might have ultimately been linked to the advertising message. The problem with this strategy is that it has been designed to become meaningful only for the brand, not for the player. The objective of encouraging players to invite their friends via Hyves was to make them give Volkswagen access to their data on the social network. However, this action was not meaningful for players, and thus they might have felt cheated. A solution would be to offer players the possibility to take the selected friends with them if they get to participate in the real event.

\section{Tem de Tank's Persuasive Structure}

After analyzing all the persuasive dimensions of Tem de Tank I conclude that the persuasive structure of the game is composed of seven persuasive dimensions. See Figure 23, the dimensions in grey were not used in this case.

By analyzing the persuasive structure and also by taking into consideration the flaws in the use of the different persuasive dimensions, I can conclude that the lack of understanding of how digital games can be used to persuade players resulted in a persuasive structure in which the second and third levels of persuasion are wasted. Most of the problems in the design of the persuasive structure of Tem de Tank come from a strategy that establishes a clear relationship between game goals and advertising goals but that ultimately does not result in a gameplay in which all the elements and the relationships between them are in keeping with both sets of goals at the same time. This might have been the result of thinking about the design of those elements in isolation while ignoring the possible meanings of the relationships between them. There also seems to be an ignorance or disinterest in the persuasive potential of the third level of persuasion.

The result is an advergame which had great potential to become effective in terms of persuasion but that might have become meaningless for a lot of its players. When I say that it had great potential to become effective I mean that the starting points were all in favor of the brand. VW's credibility is high, the target is the ideal one to whom to convey an advertising message using a digital game, and the advergame's goals were perfectly designed 


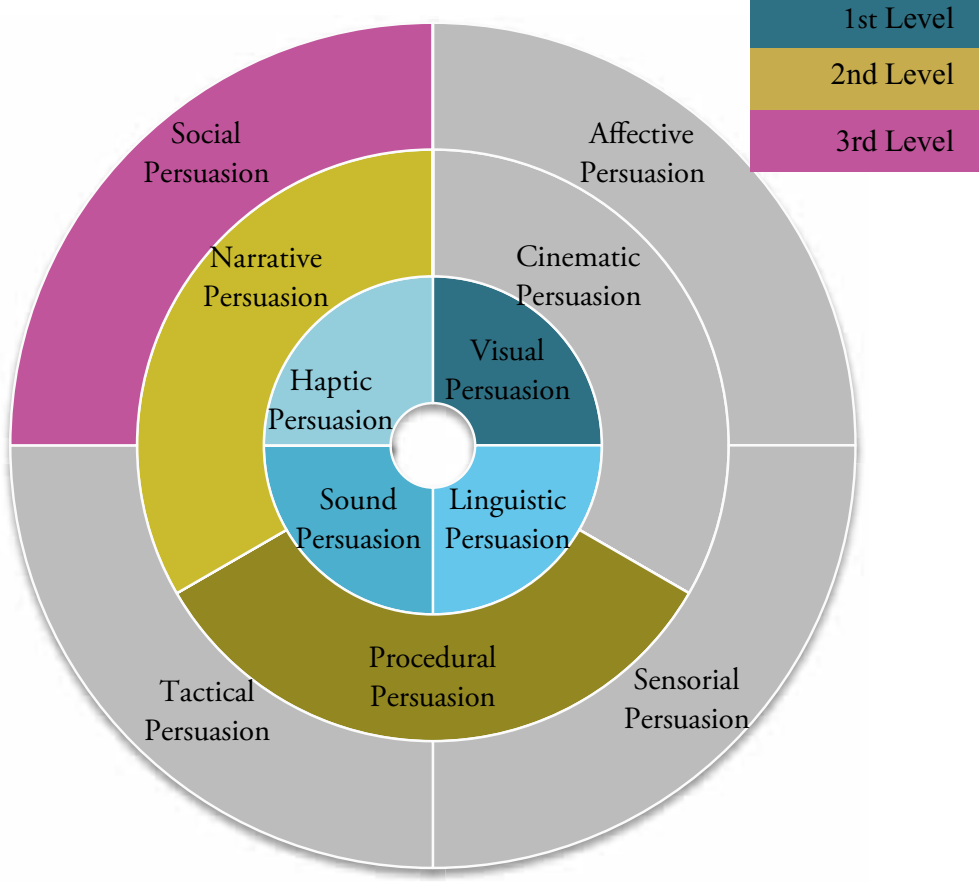

Figure 23. Persuasive structure of Tem de Tank (DDB Amsterdam \& Flavour, 2010).

to convey the advertising message. Furthermore, the quality of the visual design of the game might have also aroused positive feelings toward it. Finally, the possibility of winning a real Polo BlueMotion was the perfect motivation to attract players to play the game.

However, multiple oversights in the design have resulted in a game that might not have achieved the purpose of conveying to players the influence drivers' performance has on fuel consumption. There is a chance that some players might not even have recognized the energy efficiency of the car. The advergame might have been beneficial for VW through increasing brand recall, and some players might have had a positive memory of the game thanks to the physical challenge which came out of it. However, ideally advergames should work without any prize promised after the game because having fun playing them should be enough reward for players. If players play an advergame unwillingly and only attracted by the final prize, the persuasive potential of digital games is being neglected. 


\section{References}

DDB Amsterdam, \& Flavour (2010). Tem de Tank [Digital Game].

ISFE. (2012). Videogames in Europe: Consumer Study. Netherlands: The Media, Condent and Technology Research Specialists.

Reputation Institute. (2012). 2011 Global Rep Trak: Results and Report: Reputation Institute.

van Gelder, S. (2003). Global Brand Strategy. London: Kogan Page.

Volkswagen Group (2011). Green Machine. 
